\title{
Species Composition and Phenology of Thysanoptera within Field Crops Adjacent to Cabbage Fields
}

\author{
A. M. SHELTON AND R. C. NORTH \\ Department of Entomology, New York State Agricultural Experiment Station, \\ Cornell University, Geneva, New York 14456
}

\begin{abstract}
Environ. Entomol. 15: 513-519 (1986)
ABSTRACT Studies were conducted in 1981 and 1982 to determine the general temporal occurrence of thrips in wheat, alfalfa, oat, and red clover fields adjacent to cabbage fields in upstate New York. Shifts in species composition of thrips on these crops were observed through time, and fluctuations in abundance were attributed to changes in habitat structure (e.g., maturation and senescence in wheat and oats, and cropping practices in alfalfa and red clover). All of these crops serve as a reservoir for Thrips tabaci Lindeman, which may move to and infest nearby cabbage plantings. By sampling the thrips populations within the foliage and utilizing sticky traps to monitor aerial populations, we may be able to predict the population buildup within these crops and the subsequent movement of thrips to adjacent crops.
\end{abstract}

IN THE VARIED agroecosystem typical of upstate New York and many other areas, resources for insects are distributed among patches in time and space. From a management standpoint, this will present difficulties because polyphagous insects often exploit a sequence of hosts. Our ability to predict the occurrence and abundance of an insect pest in an area or individual field will rely on an understanding of the spatial and temporal factors that influence its movement through the crop sequence.

The onion thrips, Thrips tabaci Lindeman, appears to be an example of an insect that utilizes a sequence of host plants. The onion thrips has been reported to infest numerous field and vegetable crops and, in the last 5 years, has become a major insect pest of cabbage in New York. On cabbage, thrips injury appears as a bronze discoloration and rough texture on the leaves. Although several species of thrips may be found on cabbage during the season, onion thrips causes nearly all the injury to the head. Because of the potential for injury by thrips, the difficulty in controlling them once they move into the head, and the difficulty in identifying them in the field, growers fear the presence of any thrips on the plant. The ability to forecast the arrival of onion thrips on cabbage would allow us to provide timely warnings to growers with respect to regional occurrences, to assign risk values of infestation to individual fields, to better allocate sampling resources, and thereby improve control practices. The first step in our understanding of this system, however, must be a documentation of those early season hosts that support populations of onion thrips that could invade later crops.

Cabbage is generally a late season crop in upstate New York and is normally harvested from September through November. Winter wheat, oats, and alfalfa are planted on ca. $5.5 \times 10^{5}$ ha in New
York (Anonymous 1983) and as such constitute a tremendous resource for possible early season buildup of onion thrips populations. All of these field crops have been reported to harbor onion thrips, and Shirck (1951) stated that T. tabaci populations on onions in Idaho originate from adult migrants from nearby alfalfa and clover fields. Boyce \& Miller (1954) and Wolfenbarger \& Hibbs (1958) reached similar conclusions and also implicated winter wheat as a possible source of $T$. $t a$ baci.

Beginning in 1981, we initiated studies to determine which early season crops harbor thrips populations that may become injurious to cabbage. Additionally, these studies were begun to develop a method of sampling field populations of thrips utilizing foliage and aerial sampling, to determine the species composition of thrips in these field crops, and to document the phenology and abundance of the thrips species in each of these crops.

\section{Materials and Methods}

Thysanopteran populations were monitored weekly. In 1981, one red clover, five alfalfa, and four wheat fields, all adjacent to cabbage fields and within a radius of ca. $15 \mathrm{~km}$ in Ontario County, N.Y., were sampled weekly from April through October. During 1982, the study was expanded to include an adjacent county (Monroe), and samples were taken weekly from a total of four oat, seven wheat, and four alfalfa fields from May through November. Two fields of each crop were sampled within a ca. $30-\mathrm{km}$ radius in Monroe County, while the remaining fields were located within a ca. 20$\mathrm{km}$ radius in Ontario County. Thrips populations were sampled by extraction from foliage and by captures from aerial traps. Foliage samples of wheat, oats, alfalfa, or red clover plants cut $1 \mathrm{~cm}$ 
Table 1. Terebrantian thrips species collected from foliage or sticky trap samples collected from wheat, alfalfa, oat, and red clover fields in 1981 and 1982 , Ontario and Monroe counties, N.Y.

\begin{tabular}{|c|c|}
\hline Species & $\begin{array}{l}\text { Partial list of hosts fromı } \\
\text { Stannard (1968) }\end{array}$ \\
\hline $\begin{array}{l}\text { 1. L. denticornis } \\
\text { 2. C. manicates } \\
\text { 3. T. tabaci }\end{array}$ & $\begin{array}{l}\text { Barley and other grasses } \\
\text { Hay fields, roadsides } \\
\text { Onion, tomatoes, and oth- } \\
\text { er vegetables }\end{array}$ \\
\hline 4. F. tritici & Flowers, beans, cotton \\
\hline 5. A. rufus & Grasses, grains \\
\hline 6. A. obscurtus & Corn, grasses \\
\hline 7. F. tenuicornis & Corn, grasses \\
\hline 8. A. fasciatus & Hay fields, roadsides \\
\hline 9. Thrips trehernei Priesner & $\begin{array}{l}\text { Dandelion, goatsbeard, } \\
\text { wild lettuce }\end{array}$ \\
\hline 10. Sericothrips variabilis (Beach) & Soybeans, other legumes \\
\hline 11. Sericothrips interruptus Hood & Ash, shrubs \\
\hline 12. Thrips nigropilosus (Uzel) & $\begin{array}{l}\text { Burdock, roadsides, chry- } \\
\text { santhemum }\end{array}$ \\
\hline 13. Thrips atratus (Haliday & Flowers \\
\hline 14. Baliothrips dispar Haliday & Grasses \\
\hline $\begin{array}{l}\text { 15. Taeniothrips betulae J. C. } \\
\text { Crawford }\end{array}$ & Willows, birches \\
\hline $\begin{array}{l}\text { 16. Limothrips cerealium (Hali- } \\
\text { day) }\end{array}$ & Cereal grains \\
\hline $\begin{array}{l}\text { 17. Herctnothrips femoralis (O. } \\
\text { M. Reuter) }\end{array}$ & $\begin{array}{l}\text { Greenhouse plants, sugar } \\
\text { beets }\end{array}$ \\
\hline $\begin{array}{l}\text { 18. Sericothrips spinear floridanus } \\
\text { (Watson) }\end{array}$ & Wild four-o'clock \\
\hline
\end{tabular}

The first seven species listed were collected on the majority of dates in both years. Seventeen species were collected from sticky traps, whereas only 13 were collected from foliage samples. Species 1-7 were considerably more abundant than species 8-18. Of the latter species, approximately 1,000 specimens each of $A$. fasciatus and $T$. trehernet were collected, while $S$. variabilis, $S$. interruptus, $T$. nigropilosus, and $T$. atratus were each represented by ca. 100 specimens each. B. dispar, T. betulae, and L. cerealium accounted for ca. 10 specimens each, and only one specimen each of $H$. femoralis and S. spinear floridanus was collected. These 11 species were lumped together within a miscellaneous category for presentation of data.

below ground level were placed in Berlese funnels and the thrips extracted. Each foliage sample consisted of four $320-\mathrm{cm}^{2}$ subsamples taken within a 5-m radius of the aerial trap. Aerial counts of adults were obtained from thrips captured on white, inverted styrofoam cups with a $425-\mathrm{cm}^{2}$ surface area coated with Tanglefoot. These traps provided a cylindrical trapping area, so movement onto the trap on a horizontal plane was not influenced by cardinal direction of the trap. Aerial traps were adjusted weekly to be $0.25 \mathrm{~m}$ above the crop canopy. Although captures on these traps may be influenced by wind speed and other environmental conditions, for our purposes they provided us with a general indication of species movement above the crop canopy. On the other hand, counts of thrips extracted from the foliage provided us with the general population trends of the species within the crop canopy.

The placement of aerial traps and the location of their corresponding foliage samples during 1981 consisted of eight or nine sampling sites within a field spaced equidistant from each other so that the field was divided into eight or nine equal areas. Each trap and its corresponding locations of foliage samples was placed in the middle of each area. Following 2 months of sampling, the sample means from three traps, with one trap in the center of a field and the other two in a straight line and equidistant from the center, were compared with the means from the eight to nine sites per field. By $t$ test analysis, we concluded that the means were not significantly different and the estimate of the mean drawn from three samples adequately suited the precision we were seeking. Thereafter, only three aerial traps and their corresponding foliage samples per field were utilized.

Foliage samples were collected from eight to nine sites per field throughout the 1981 season. Mean numbers of adults and larvae from foliage collected at three sample sites were compared to mean numbers from all eight or nine samples. There was no significant difference in the means, so samples were collected each week from three sites per field in 1982. All samples were returned to the laboratory where the thrips were extracted in Berlese funnels, enumerated, and identified. In 1981 , five randomly selected adult thrips per sample unit (i.e., individual trap or foliage sample) were identified to species. In 1982, all adults from foliage and aerial samples were enumerated and identified to species. Because no keys were available for differentiating thrips larvae, all larvae were combined into a single total. Data from individual fields were combined with those of other fields of the same crop and county for presentation of general population trends of the particular crop and area. General crop phenology and cultivation practices were recorded throughout the season.

\section{Results and Discussion}

Adults of 18 species of terebrantian thrips were collected during this study (Table 1). The first seven species listed were collected on the majority of dates in both years. Seventeen species were collected from sticky traps, whereas only 13 were collected from foliage samples. The relative abundance and species composition of thrips populations were significantly different in relation to the crops sampled and their phenology.

Wheat. The means from foliage and sticky trap samples from 1981 wheat fields are presented in Fig. 1. Larval populations peaked on 18 June $(\bar{x}=$ 372.0 per sample) and remained high during the following 2 weeks. Adults collected during this period from foliage reached peak numbers on 26 June ( $\bar{x}=59.4$ per sample). Subsequently, numbers of adults captured on sticky traps peaked the week of $2-9$ July $(\bar{x}=135.0$ per sample). The wheat fields were ripening from 26 June through the 9 July sampling periods and all four fields were harvested the week of 9-16 July. Generally, the same species were found in foliage and on traps. Collections from middle and late spring were 

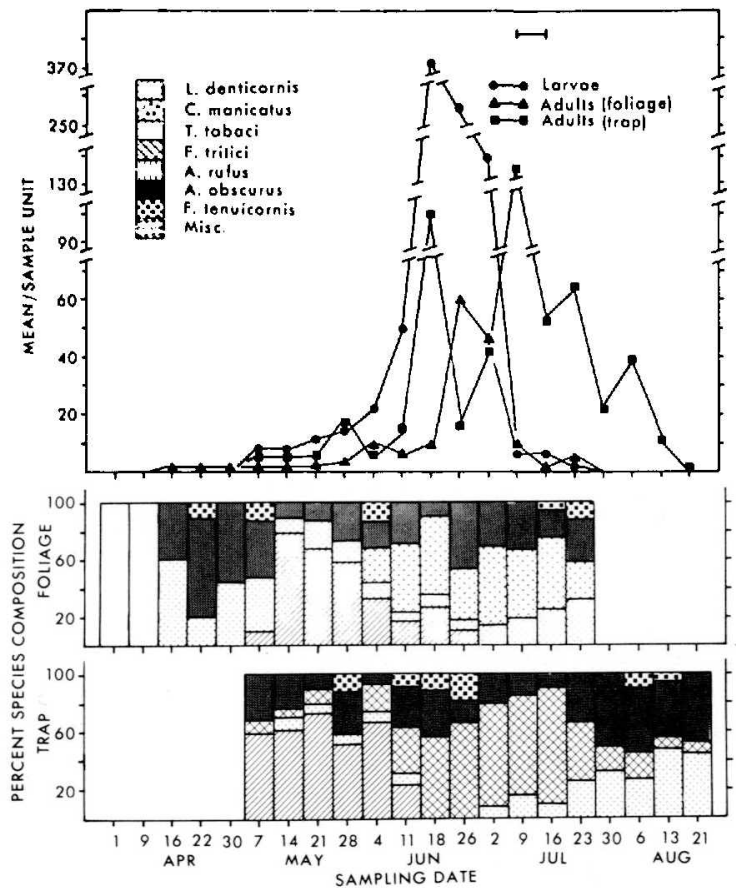

Fig. 1. Means and species composition of thrips collected from foliage and sticky trap samples from wheat fields in 1981, Ontario County. $\longmapsto$, harvest.

dominated by Limothrips denticornis (Haliday), T. tabaci, Frankliniella tritici (Fitch), and Anaphothrips obscurus (Müller). Before harvest, F, tritici dominated in both counts. Following harvest of the wheat, species composition shifted and subsequent counts were dominated by $A$. obscurus and $T$. tabaci. The maturation, senescence, and subsequent harvest of wheat may have caused
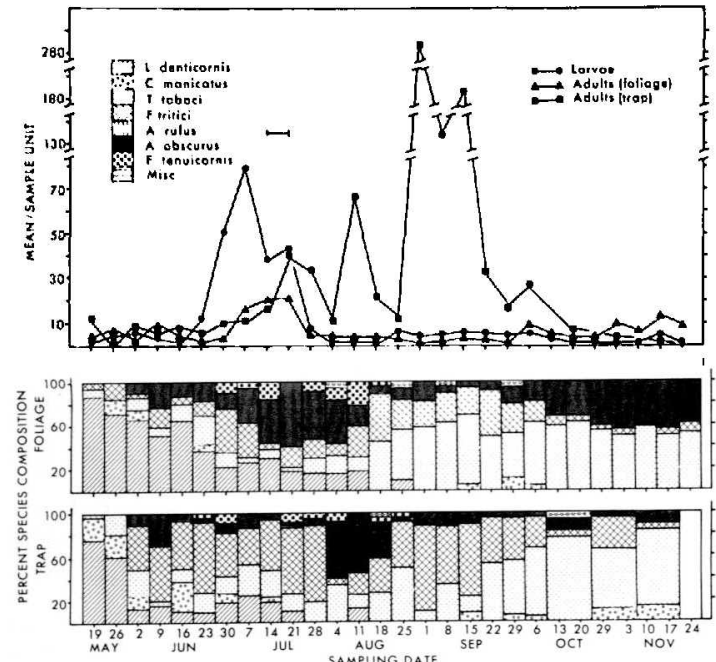

Fig. 2. Means and species composition of thrips collected from foliage and sticky trap samples from wheat fields in 1982, Ontario County. $\longmapsto$, harvest.

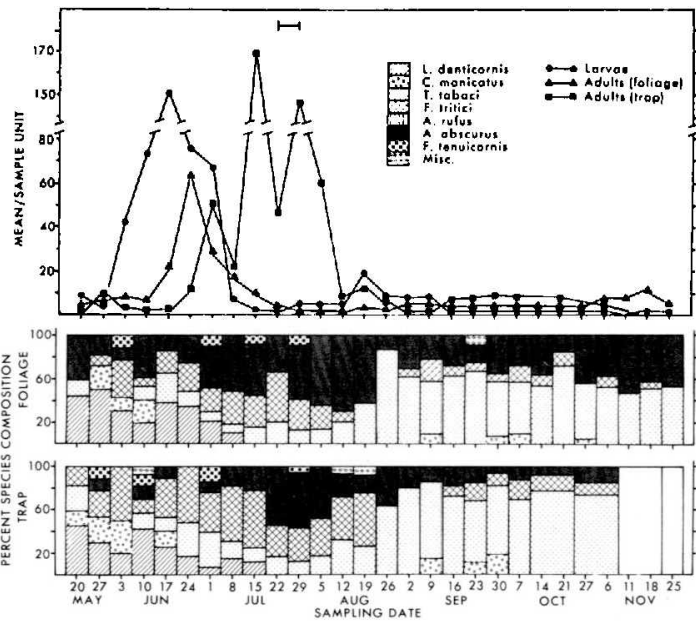

Fig. 3. Means and species composition of thrips collected from foliage and sticky trap samples from wheat fields in 1982, Monroe County.

adults to fly to new hosts and caused the precipitous decline of thrips in the foliage counts. The early season peak of 11-18 June on traps, although less distinct, could have been the result of several factors. It may have been produced by the movement of the first generation of several early season species or it may have been produced by longdistance migration of one or more species.

Buildup of thrips populations was delayed in 1982 compared with 1981. Larval populations recorded within wheat fields in Ontario County peaked on 7 July ( $\bar{x}=77.1$ per sample) (Fig. 2). Coincidental with harvest, which took place the week of 14-21 July, adult counts in the foliage and on sticky traps reached means of 19 adults per sample and 40.5 adults per sample, respectively. Foliage counts plunged to a mean of $<10$ larvae
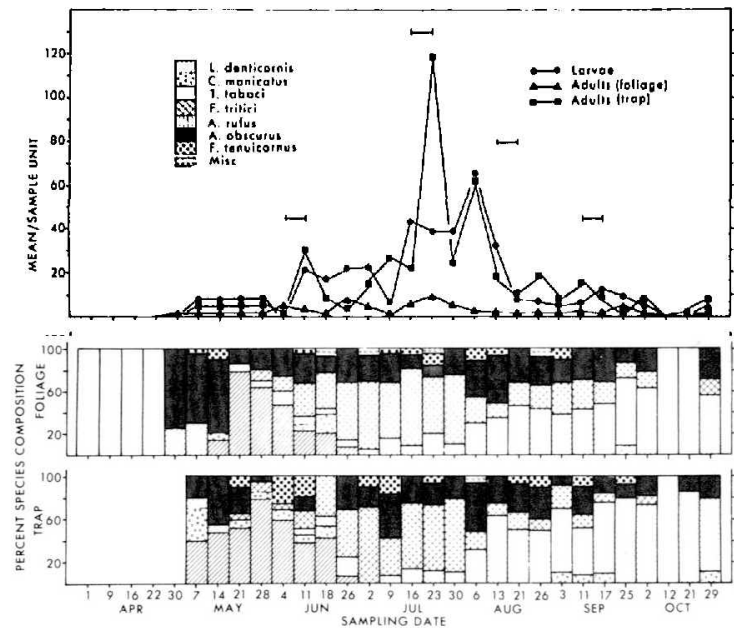

Fig. 4. Means and species composition of thrips collected from foliage and sticky trap samples from alfalfa fields in 1981, Ontario County. 

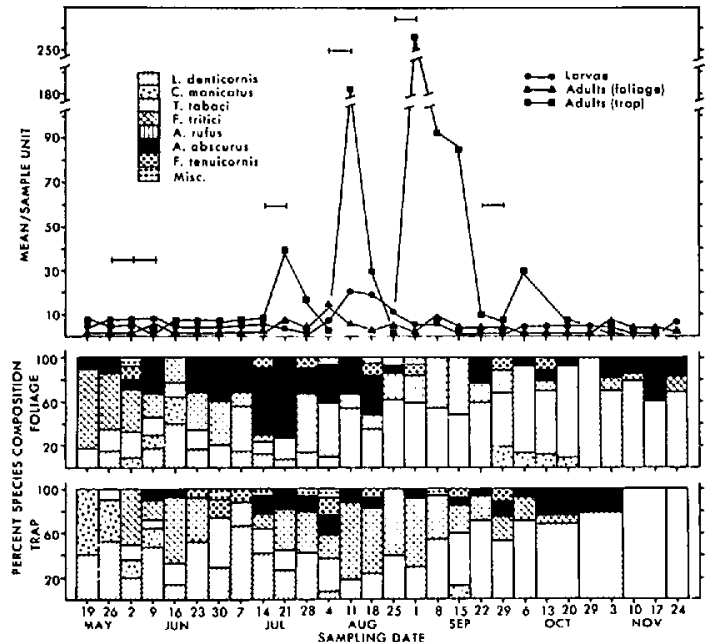

Fig. 5. Means and species composition of thrips collected from foliage and sticky trap samples from alfalfa fields in 1982, Ontario County.

or adults per sample and maintained this low count through November. Trap counts exceeded the preharvest maximum count during the week of 4-11 August and from 25 August through 15 September $(\bar{x}=281.7$ per sample). Shifts in species composition followed the same general trends as in 198.1. T. tabaci was present in moderate numbers during the season and was found in volunteer wheat from late summer until it was plowed the following spring. From the data so far examined, it is not yet possible to account for the large flight of thrips over the wheat stubble in late August and September.

Populations increased nearly a month earlier in Monroe County compared with Ontario County (Fig. 3). Larval populations quickly rose to a peak on 17 June ( $\bar{x}=149.8$ per sample) and remained elevated until 8 July. Increases in adult populations, from both foliage samples and trap counts, followed 3-4 weeks behind the increase in larval populations. The wheat was harvested the week of 22-29 July. The decline during the week of 1-8 July of all three counts and the rise of the trap counts to a peak the following week appear to be related to the maturation and the delayed harvest of the wheat. Most of the adults had left the wheat by the week of 8-15 July. A large flight the week of 22-29 July may have been related to an adjacent oat field, as a large percentage of the species composition consisted of $A$. obscurus, which dominated in oat fields. Late season volunteer wheat once again supported a significant population of T. tabaci in late summer and early fall.

Alfalfa. Trends from the samples obtained from alfalfa fields in 1981 (Fig. 4) indicated lower overall thrips populations and a later occurrence in time than in wheat. Larval populations increased in the first few weeks of June, peaked on 6 August

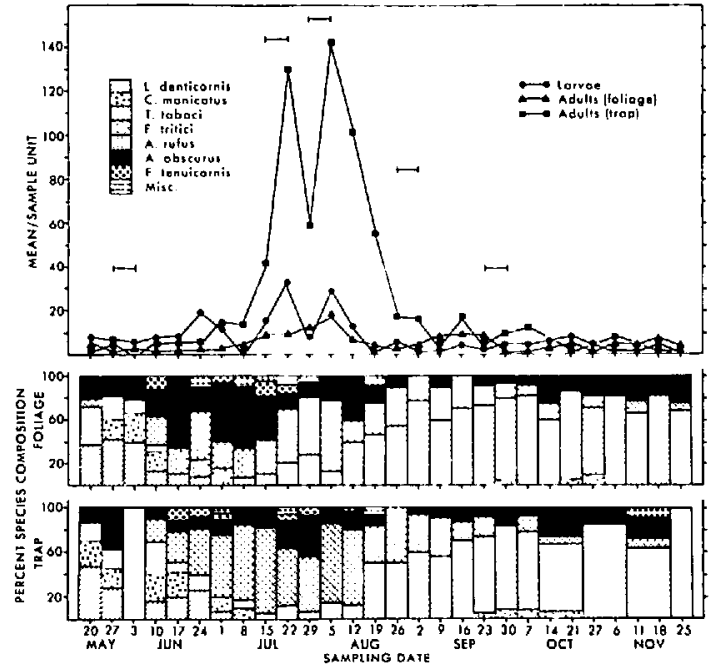

Fig. 6. Means and species composition of thrips collected from foliage and sticky trap samples from alfalfa fields in 1982, Monroe County. $\longmapsto$, harvest.

$(\tilde{x}=64.8$ per sample), and dropped below a mean of 10 larvae per sample throughout September and October. Adult populations in the foliage never increased above a mean of 10 adults per sample and did not show any obvious relationship to larval numbers and adult trap counts. A small but distinct peak of adults was recorded from traps the week of 4-11 June. The maximum number of thrips was captured on traps the week of 16-23 July $(\bar{x}=118.8$ per sample), with another welldefined peak the week of 30 July- 6 August. The alfalfa fields were harvested four times during the weeks of 4-11 June, 16-23 July, 13-21 August, and 11-17 September 1981. The first two peaks of

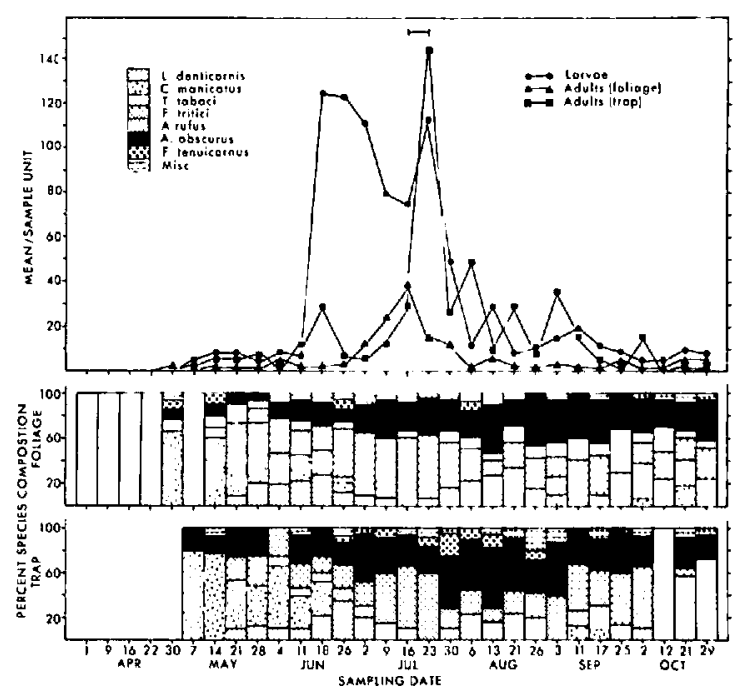

Fig. 7. Means and species composition of thrips collected from foliage and sticky trap samples from a red clover field in 1981, Ontario County. $\longmapsto$, harvest. 


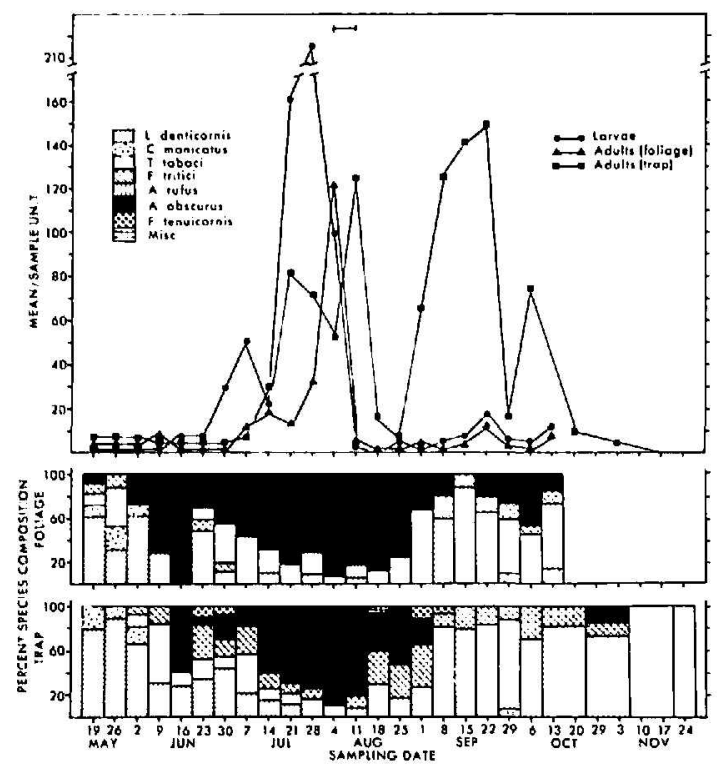

Fig. 8. Means and species composition of thrips collected from foliage and sticky trap samples from oat fields in 1982, Ontario County.

adults captured on traps appeared to correspond to the cutting of alfalfa, but the thrips populations did not respond so dramatically following the last two cuttings. L. denticornis, A. obscurus, $F$. tenuicornus (Uzel), and T. tabaci overwinter in this area (unpublished data) and are the predominant species collected in the spring. $F$. tritici prevails from early through midsummer and then is replaced by $T$. tabaci and A. obscurus from midsummer through midfall. $T$. tabaci is present in low numbers until early August, at which time it becomes the dominant species for the rest of the season.

As was the case in 1981, larval and especially adult populations within the alfalfa foliage remained quite low in Ontario County in 1982 (Fig. 5). Four distinct peaks were recorded from sticky trap counts. The first three peaks recorded from traps corresponded to cutting and harvest dates. The prolonged flights of 25 August-15 September and the small peak the week of 29 September-6 October did not appear to be directly related to the cutting and harvest of alfalfa. It also seems likely (from the larval and adult foliage counts) that these flights in September and October were the result of a large migration of thrips out of or into alfalfa foliage. A great deal of movement within and between fields seems to be consistent with the numbers captured on the sticky traps.

Data collected from alfalfa fields in Monroe County (Fig. 6) were similar to those obtained from other alfalfa fields, although Monroe County again appeared to have earlier population buildups. The foliage samples never contained large numbers of larval and adult thrips as was observed in wheat and oats. The foliage counts reached a peak in
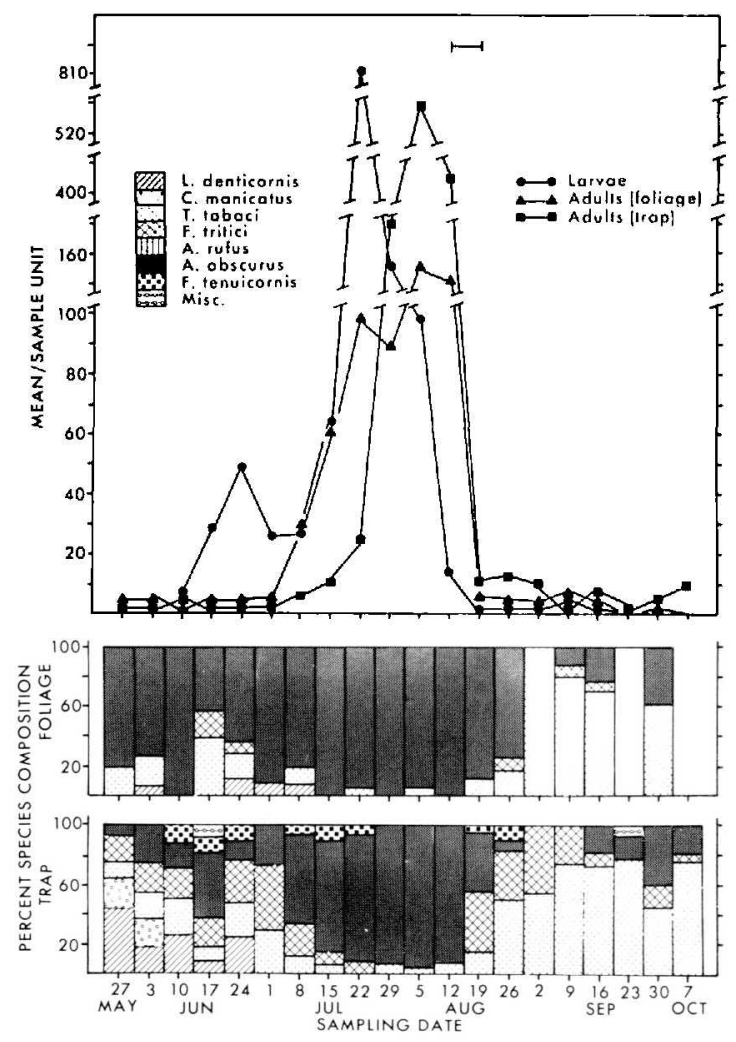

Fig. 9. Means and species composition of thrips collected from foliage and sticky trap samples from oat fields in 1982, Monroe County.

July, as was observed in other alfalfa fields. Adults that were captured on traps reached a peak in July and early August. The week of $15-22$ July $(\bar{x}=$ 127.7 per sample) and 20 July-5 August $(\bar{x}=134.2$ per sample) coincided with the cutting of the alfalfa. Two fields were cut the week of 27 May-3 June, one the week of 15-22 July, one 29 July-5 August, one 26 August-2 September, and one the week of 23-30 September. Through early August, F. tritici and A. obscurus were the dominant species. T. tabaci again predominated from midsummer through late fall in the foliage and on the traps.

Red Clover. The data collected from red clover revealed trends that are quite similar to those observed in wheat and alfalfa (Fig. 7). Larval populations rose rapidly to an early season peak on 18 June $(\bar{x}=124.7$ per sample) and remained $>50$ per sample through 30 July. Peak numbers of adults sampled from the foliage occurred on 16 July $(\bar{x}=$ 37.1 per sample) and of thrips collected from sticky traps on the week of $16-23$ July $(\bar{x}=143.3)$. The large numbers of adults collected on sticky traps during the week of 16-23 July corresponded to the cutting of red clover on 17 July. Red clover appeared to harbor a larger diversity of thrips species than wheat or alfalfa, as indicated by the miscellaneous category that contributed a higher 
proportion of the thrips sampled from red clover than from other crops. A majority of these thrips were a known thrips predator, Aeolothrips fasciatus (L.) (Stannard 1968). Chirothrips manicatus Haliday dominated the spring sampling period, but a large number of other species were present throughout the spring and summer. $F$. tritici and $A$. obscurus were in the majority throughout the summer and fall sampling period. $T$. tabaci was not a predominant species collected from red clover fields. Only beginning in August did T. tabaci represent a significant proportion of the species composition. The frequency of capture of $T$. $t a-$ baci from foliage samples and trap counts was much less than that recorded from wheat and alfalfa.

Oats. Numbers of larvae reached a peak on 28 July ( $\bar{x}=214.2$ per sample) in Ontario County, decreased by one-half the following week, and dropped to a mean of $<10$ larvae per sample until a sufficient quantity of volunteer oats was present and could support higher numbers through September (Fig. 8). Counts of adults extracted from the foliage closely paralleled the increase in larval counts but occurred a week later, peaking on 4 August ( $\bar{x}=121.7$ per sample). Counts of larvae and adults from foliage were continued until the volunteer oats were tilled in October. Numbers of adult thrips captured on sticky traps before harvest paralleled the larval and adult foliage counts at an interval of 2 weeks and 1 week, respectively, and reached a peak the week of 4-11 August $(\bar{x}=$ 123.3 per sample). The oat fields were harvested the week of 4-11 August, which corresponded to the maximum number of adults captured on traps and with the rapid decline of thrips in the foliage samples. Before harvest, adult thrips had been flying for at least 4 weeks. Even though $L$. denticornis, $C$. manicatus, and $T$. tabaci were present in the spring samples, $A$. obscurus was the dominant species, with a small proportion of Aptinothrips rufus (Gmelin) recovered from the foliage. As previously reported for the wheat and alfalfa fields of Ontario County, there was a large flight of thrips during early September. Again, it seems unlikely that this large number of thrips originated from the volunteer oats because numbers of larvae and adults in foliage samples were never very high. $T$. tabaci was the dominant species captured on aerial traps in oat fields during September.

Populations of larvae in Monroe County quickly rose to a peak on 22 July ( $\bar{x}=811.2$ per sample) and in less than a month dropped below a mean of 10 larvae per sample (Fig. 9). Adults collected from oat foliage reached a peak on 5 August $(\bar{x}=$ 155.0 per sample) from a relatively high level during the previous 2 weeks, and remained near peak numbers the following week. Captures on sticky traps were high for 3 weeks and reached a peak the week of 29 July-5 August $(\bar{x}=527.0$ per sample). The oat fields were harvested the week of 12-19 August. It appears that the majority of adult thrips had left the fields in the 3 weeks before harvest. $A$. obscurus was the dominant species in the foliage samples and in the trap counts during the 3 weeks before harvest when the grain was maturing.

General Trends. A peak in numbers of thrips captured on sticky traps during 4-18 June was recorded from all three crops surveyed in 1980. This may have resulted from movement during favorable environmental conditions of early season thrips (e.g., L. denticornis, C. manicatus, A. obscurus, and $F$. tenuicornus) following their first complete generation. It also may have been a record of a much longer migration (i.e., originating in southern latitudes) of $F$. tritici. $F$. tritici, one of the more abundant species at that time, is not known to overwinter in northern latitudes and has been documented from captures in wind traps to migrate into Illinois in early May (Stannard 1968). During May, F. tritici and A. obscurus were the dominant species collected from all three crops in the present study.

When data for thrips captured in aerial traps were combined (1981-82), the highest numbers were recorded during the $2-3$ weeks before the harvest of wheat and oats. Wheat was harvested the week of 9-16 July in 1981, 14-21 July in 1982 in Ontario County, and 22-29 July in Monroe County, and the peak flight periods occurred just before these dates. The majority of adult thrips captured at this time were $F$. tritici and $A$. obscurus, with several other species contributing a small percentage of the total. It appears that $T$. tabaci is present throughout the season but does not become a large component of the thysanopteran community in these crops until middle to late summer. However, this should not be construed as a suggestion that the low numbers in the spring and early summer are not sufficient to infest adjacent cabbage fields during the growing season.

There appears to be a relationship between the second and third cuttings of alfalfa and the movement of thrips. The data presented in Fig. 4-6 are population means from all fields of alfalfa sampled. When population trends for individual fields are examined, the relationship between cutting and movement of thrips in a particular field is even more striking. The abrupt peaks in numbers of adults caught on traps were not so clearly correlated with peaks of adults from foliage samples. It is possible that peak numbers captured on traps in alfalfa were caused by thrips that originated from other sources, although the samples from alfalfa foliage contained the same general species composition as the trap counts during this period (i.e., predominately $F$. tritici and A. obscurus). A more likely explanation would be that, when an entire field of alfalfa is cut, the food resource quickly becomes unsuitable and the adult thrips within that field leave to search for new hosts.

One particular unresolved observation is the large number of thrips captured in September 
1982 in Ontario County. F. tritici, A. obscurus, and $T$. tabaci predominated at that time in traps from all three crops. Since there did not appear to be sufficient quantities of larvae or adults within the foliage of these crops to account for that light, it is tentatively concluded that they originated from some other source. These three species of thrips are very catholic in their choice of host plants (Stannard 1968), so there may very well be several yet undiscovered sources. Favorable weather and a movement to overwintering sites may also account for this phenomenon.

In conclusion, shifts in species composition on these crops were observed through time, and we attributed these shifts to changes in habitat structure (e.g., maturation and senescence in wheat and oats, and cropping practices in alfalfa and red clover). Other researchers working with similar species of thrips have noted that when these unfavorable conditions occurred, massive flights of thrips were observed (Tansky 1958, Post \& Olson 1960). The crops that we monitored may all have been serving as reservoirs for $T$. tabaci before it appeared in cabbage, and knowledge of the phenology of $T$. tabaci in these crops may help us predict its occurrence in nearby plantings of cabbage.

\section{Acknowledgment}

We thank W. T. Wilsey for field assistance, and S. Nakahara (Systematic Entomology Lab., USDA) for as- sistance in thrips identification. We also thank D. F. Cox (Department of Statistics, Iowa State Univ.) for his timely assistance with the statistical analysis.

\section{References Cited}

Anonymous. 1983. New York State agricultural statistics 1983. New York Crop Reporting Service, Albany, N.Y.

Boyce, K. E. \& L. A. Miller. 1954. Overwintering habitats of the onion thrips, Thrips tabaci Lind. (Thysanoptera: Thripidae), in southwestern Ontario. Annu. Rep. Entomol. Soc. Ont. 84: 82-86.

Post, R. L. \& G. Olson. 1960. Barley thrips-1960. N.D. Seed J. 29(3): 3.

Shirck, F. H. 1951. Hibernation of onion thrips in southern Idaho. J. Econ. Entomol. 44: 1020-1021.

Stannard, L. J. 1968. The thrips or Thysanoptera of Illinois. Ill. Nat. Hist. Surv. Bull. 29(4): 1-552.

Tansky, V. I. 1958. Comparative infestation of varieties of spring wheat by the wheat thrips, Haplothrips tritici Kurd., and its injuriousness in northern Kazakhstan. Tr. Vses. Inst. Zashch. Rast. 11: 7-25 (in Russian).

Wolfenbarger, D. \& E. T. Hibbs. 1958. Onion thrips (Thrips tabaci Lind.) infesting cabbage. J. Econ. Entomol. 51: 394-396.

Received for publication 12 December 1984; accepted 27 January 1986. 